\title{
Morphology-Controlled High-Efficiency Small Molecule Organic Solar Cells without Additive Solvent Treatment
}

\author{
Il Ku Kim ${ }^{1, *}$, Jun Hyung Jo ${ }^{2}$ and Jung-Ho Yun ${ }^{3}$ \\ 1 National Photonics Semiconductor Lab, National Photonics Semiconductor Inc., Suwon-Si 17113, Korea \\ 2 School of Information and Communication Technology, Griffith University, Southport QLD 4222, Australia; \\ j.jo@griffith.edu.au \\ 3 Nanomaterials Centre, School of Chemical Engineering, University of Queensland, Brisbane QLD 4072, \\ Australia; j.yun1@uq.edu.au \\ * Correspondence: cto.np@npsemi.com; Tel.: +82-31-907-7950
}

Academic Editor: Guanying Chen

Received: 23 February 2016; Accepted: 29 March 2016; Published: 8 April 2016

\begin{abstract}
This paper focuses on nano-morphology-controlled small-molecule organic solar cells without solvent treatment for high power-conversion efficiencies (PCEs). The maximum high PCE reaches up to $7.22 \%$ with a bulk-heterojunction $(\mathrm{BHJ})$ thickness of $320 \mathrm{~nm}$. This high efficiency was obtained by eliminating solvent additives such as 1,8-diiodooctane (DIO) to find an alternative way to control the domain sizes in the BHJ layer. Furthermore, the generalized transfer matrix method (GTMM) analysis has been applied to confirm the effects of applying a different thickness of BHJs for organic solar cells from 100 to $320 \mathrm{~nm}$, respectively. Finally, the study showed an alternative way to achieve high PCE organic solar cells without additive solvent treatments to control the morphology of the bulk-heterojunction.
\end{abstract}

Keywords: small molecule; organic solar cell; bulk-heterojunction; optical simulation

\section{Introduction}

During the last decades, bulk-heterojunction (BHJ) small-molecule organic solar cells (OSCs) have received more research attention [1-9]. BHJ OSCs have interpenetrating networks in a blend of conjugated organic donors and fullerene-derivative acceptors for their alternative potential in obtaining low-cost clean energy solutions [1-6]. Among the many research issues, surface morphology control is an essential part of the spin-coating process to form thin films to get high-efficiency OSCs [2]. In the BHJ photoactive layer, the ultrafast photo-induced charge transfer at the interface of the phase-separated acceptor and donor is also needed for the high performance of OSCs before charge recombination has happened [10-12]. However, despite polymeric BHJ OSCs reported with high power conversion efficiencies (PCEs), others have pointed out some drawbacks. For instance, the organic polymer has batch-to-batch variations, molecular weight differences, polydispersity and impurity which could lead to a major obstacle for high-performance organic solar cells [2,13-15]. To address the above issues, small-molecule BHJs (SM BHJs) were introduced [1-5,8].

In contrast, it has been reported that solution-processed small-molecule BHJ solar cells have a well-defined molecular structure with intermediate dimensions [1,2]. Examples of solution-processed SM BHJ OSCs with PCEs ranging from $6.7 \%$ to $8.01 \%$ have been reported with a 1,8-diiodooctane (DIO) additive solution [1-4]. These results were mainly obtained from the morphological control of the $\mathrm{BHJ}$ layer in terms of the additive solvent treatment. However, there are major concerns surrounding morphology control by using an additive solution such as the optimization of solution ratio control, and a limited number of applicable matching solutions (i.e., chlorobenzene, 1,2-dichlorobenzene) [1-4]. 
In addition, the usage of a solvent additive affects unexpected solar cell performance. To avoid this, a study suggests the treatment of the active layer by drying speed or washout with methanol [16]. However, this is also not the fundamental method to solve the additional solvent problem issue. Therefore, it does not always guarantee a high efficiency of OSCs. Furthermore, strong aggregation is another problem during the spin-coating process used to produce a high quality of thin film for SM BHJs [2].

In this paper, we report solution-processed high-efficiency SM BHJ OSCs without a DIO additive solvent treatment. For that, a well-developed small-molecular donor $\left(p\right.$-DTS $\left.\left(\mathrm{FBTTh}_{2}\right)_{2}\right)$ will be applied [1-5]. This small-molecule donor has good characteristics of excellent solubility in organic solvents, strong optical absorption $(600-800 \mathrm{~nm})$ and a good hole mobility $\left(\approx 0.1 \mathrm{~cm}^{2} / \mathrm{Vs}\right)$ [2]. Furthermore, a generalized transfer matrix method (GTMM) for the optical modeling analysis result will be introduced to confirm the behavior of light absorption in the $\mathrm{BHJ}$ photoactive layer of different thicknesses [17-19].

\section{Experimental Section}

To address the particular issues mentioned above, OSCs fabricated through the incorporation of a donor-acceptor blend of $p$-DTS(FBTTh $)_{2}$ and $[6,6]$-phenyl- $\mathrm{C}_{71}$-butyric-acid-methyl-ester $\left(\mathrm{PC}_{70} \mathrm{BM}\right)$ to form a BHJ photoactive layer. Chemical structures for OSC showed in Figure 1a. $p$-DTS(FBTTh $)_{2}$ and $\mathrm{PC}_{70} \mathrm{BM}$ were dissolved in chlorobenzene $(\mathrm{CB})$ and stirred over $24 \mathrm{~h}$ with a total concentration of $50 \mathrm{mg} / \mathrm{mL}$. Indium tin oxide (ITO)-coated glass substrates were cleaned sequentially by ultrasonic treatment in Alconox detergent, deionized water, acetone and isopropyl alcohol. A polymeric conducting thin layer of PEDOT:PSS (40 nm) was spun-cast on top of the ITO-coated glass substrate. Before spin-coating of $\mathrm{BHJ}$ thin film, co-dissolved donor-acceptor blend was heated at $100^{\circ} \mathrm{C}$ for $30 \mathrm{~min}$. Then the $p$-DTS(FBTTh $)_{2}: \mathrm{PC}_{70} \mathrm{BM}$ BHJ layer was spin-cast from the heated and blended solution with different spin speed to form a different thickness of BHJs from 300 to $2000 \mathrm{rpm}$. During the solution preparation and film formation processes, 1,8-diiodooctane (DIO) additive solvent treatment was avoided. Finally, $\mathrm{Ca}(5 \mathrm{~nm})$ and $\mathrm{Al}(100 \mathrm{~nm})$ electrodes were deposited on top of $\mathrm{BHJ}$ photoactive layer (Figure 1b). Post-annealing process is also not applied for all devices. The energy band diagram of SM BHJ OSC showed in Figure 1c. Electrical characterization of all OSCs had done in the air after encapsulation. A commercial $J-V$ and external quantum efficiency (EQE) characterization system was supplied by PV Measurement Inc. (Boulder, CO, USA) to obtain the data. A GTMM analysis was accomplished to calculate and analyse the multi-layered interface OSCs. For transfer matrix analysis, optical constants of all layers have been obtained by the ellipsometry method. Finally, the nano-morphology of BHJ film was investigated by atomic force microscopy (AFM). 
a)
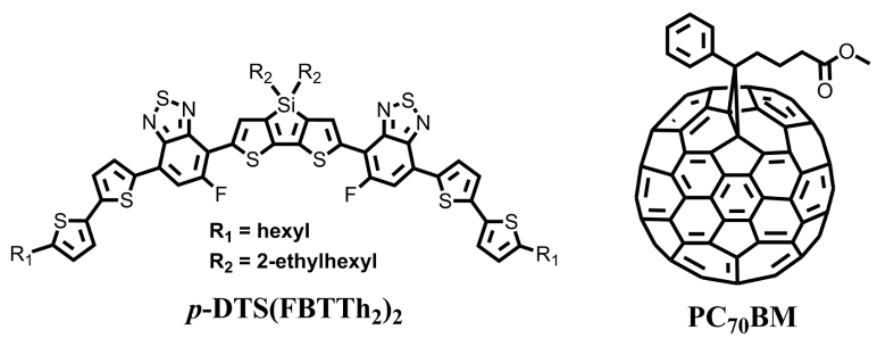

b)

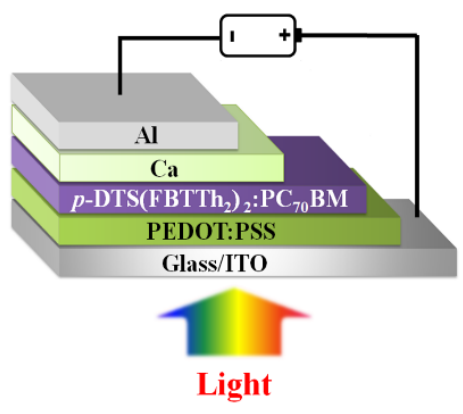

c)

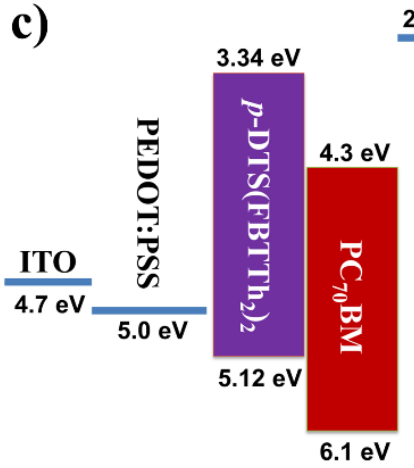

$\frac{2.9 \mathrm{eV}}{\mathrm{Ca}}$

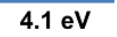

Al

Figure 1. (a) Chemical structures of $p$-DTS(FBTTh $)_{2}$ and $\mathrm{PC}_{70} \mathrm{BM}$; (b) device architecture for small-molecule bulk-heterojunction organic solar cells (SM BHJ OSCs); (c) band diagram of SM BHJ OSCs.

\section{Results and Discussion}

SM BHJ OSCs have been tested under simulated $100 \mathrm{~mW} / \mathrm{cm}^{2}$ Air Mass (AM) 1.5G illumination. The optimized ratio of the small molecule donor $\left(p\right.$-DTS $\left.\left(\mathrm{FBTTh}_{2}\right)_{2}\right)$ to $\mathrm{PC}_{70} \mathrm{BM}$ was chosen to be the same as the reported ratio $(60: 40 w / w)$ [1]. Device current density/voltage $(J-V)$ characteristics of SM $\mathrm{BHJ}$ OSCs, in terms of BHJ without DIO treatment, with different photoactive thicknesses are shown in Figure 2.

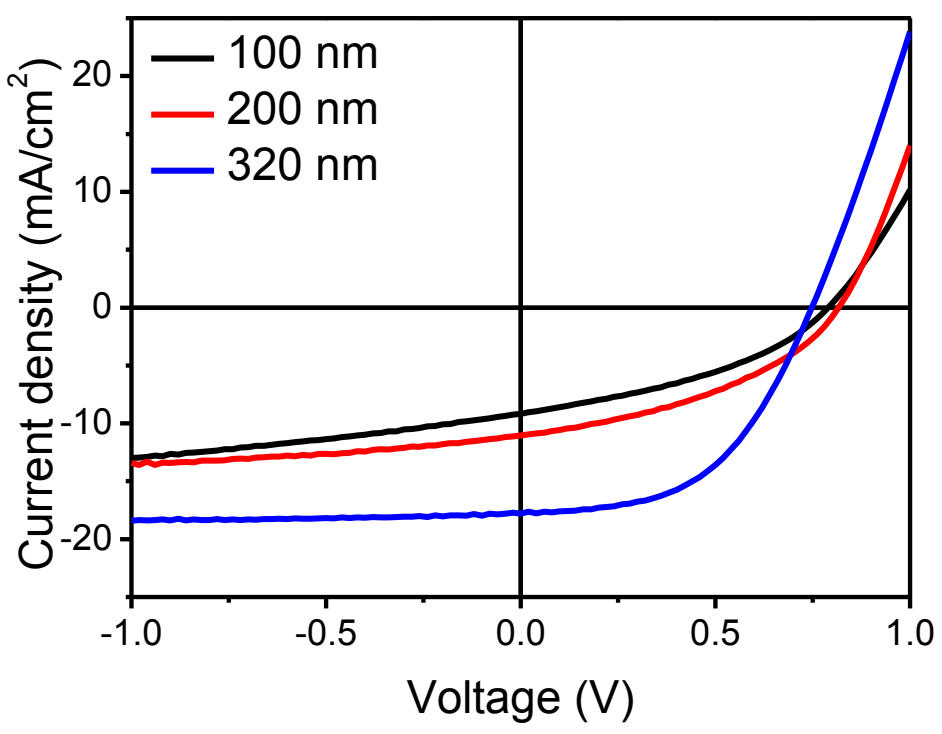

Figure 2. Measured density/voltage $(J-V)$ curves of SM BHJ OSCs.

A $V_{\text {oc }}$ as high as $0.74 \mathrm{~V}$ was observed in all devices. Combined with its high $J_{\mathrm{sc}}$ and fill factor $(F F)$, a high power conversion efficiency (PCE) of $6.83 \%$ on average was measured with 320-nm-thick 
devices and the highest PCE was measured at $7.22 \%\left(V_{\mathrm{oc}}=0.74 \mathrm{~V}, J_{\mathrm{sc}}=18.23 \mathrm{~mA} / \mathrm{cm}^{2}, F F=0.54\right)$. The measured PCE of our device $(2.78 \%)$ is much greater than the reported PCE value $(1.8 \%)$ with the same BHJ thickness of $100 \mathrm{~nm}$ [1]. It is strong evidence to confirm that an additive solvent such as DIO is not an essential part for controlling the device performance, while the majority of the research groups have focused on using an additive solvent to control the $p$-DTS(FBTTh $)_{2}$ and small molecule donor materials.

The EQE spectra were obtained to confirm the accuracy of the SM BHJ OSC's photo-generated J- $V$ result. The results are shown in Figure 3. Significantly, an EQE over $70 \%$ was achieved with a $320 \mathrm{~nm}$ $\mathrm{SM} \mathrm{BHJ}$ photoactive layer from a wavelength range of $350-700 \mathrm{~nm}$. A $1.5 \mathrm{G}$ spectrum was applied to calculate the $J_{\mathrm{sc}}$ value by integrating the EQE data. The calculated $J_{\mathrm{sc}}$ values are in good agreement with the directly measured values. Furthermore, these EQE spectra confirm Beer-Lambert law by increasing the photoactive layer thicknesses. It is good to note that EQE spectra results obtained much better results to compare with the literature $[1,3,4,8]$. A summary of the SM BHJ OSCs' performance is shown in Table 1.

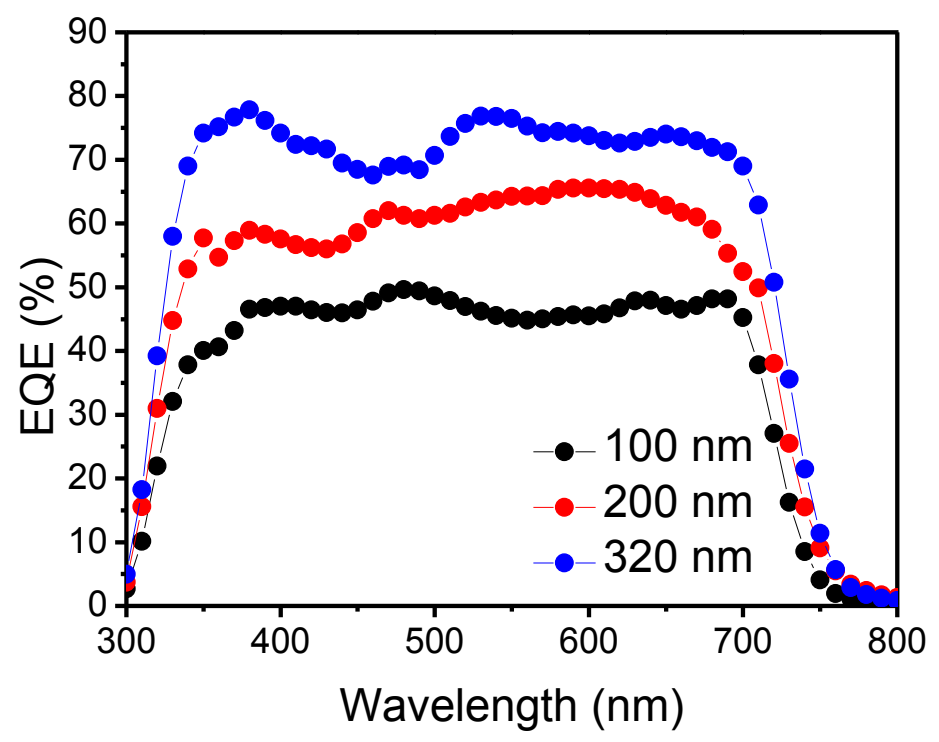

Figure 3. Measured external quantum efficiency (EQE) spectra of SM BHJ OSCs.

Table 1. A summary of SM BHJ OSC performances with changes of BHJ thickness. (PCE: Power conversion efficiency.)

\begin{tabular}{ccccc}
\hline BHJ Thickness & $\boldsymbol{V}_{\mathbf{~ o c}}(\mathbf{V})$ & $J_{\mathbf{s c}}\left(\mathbf{m A} / \mathbf{c m}^{\mathbf{2}}\right)$ & Fill Factor & PCE (\%) \\
\hline $100 \mathrm{~nm}$ & 0.78 & 9.2 & 0.39 & 2.78 \\
$200 \mathrm{~nm}$ & 0.80 & 11.1 & 0.41 & 3.64 \\
$320 \mathrm{~nm}$ & 0.74 & 17.8 & 0.52 & 6.83 \\
\hline
\end{tabular}

Figure 4 shows the calculated charge generation rate $\left(\mathrm{in} \mathrm{s}^{-1} \cdot \mathrm{cm}^{-3}\right)$ of SM BHJ OSCs obtained by the generalized transfer matrix method (GTMM). These calculated charge generation rate results provide a further explanation as to why a thicker junction of OSC has a higher $J_{\mathrm{sc}}$ value than a thinner junction of OSCs. From Figure 4a, the peak charge generation rate is located in the middle of the SM BHJ. In comparison with Figure $4 b, c$, the charge generation rate has the highest value in 100-nm-thick $\mathrm{BHJ}$. However, under the thin junction circumstance, there is interference between the forward direction waves by absorption from the glass side and the backward direction waves by reflections from the electrodes in the photoactive layer. Therefore, the interference effect brings a low $J_{\mathrm{sc}}$ value in thin junction OSCs. By increasing the photoactive layer thickness containing $\mathrm{BHJ}$, the OSC follows 
Beer-Lambert law. Therefore, the photo-generation rate is exponentially decreased by increasing the photoactive layer thickness.
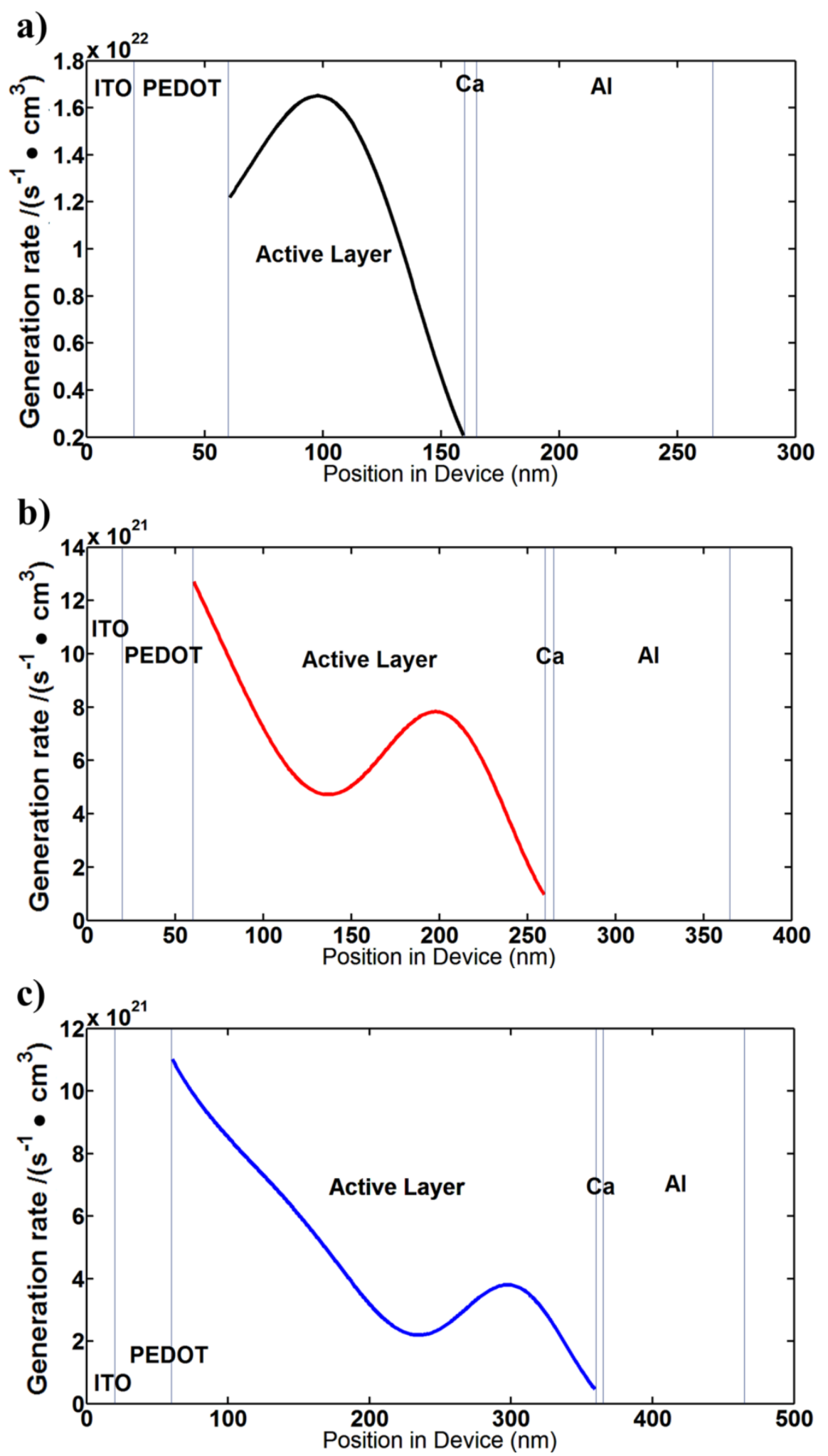

Figure 4. Simulation results of charge generation rates of SM BHJ OSCs: (a) BHJ active layer $=100 \mathrm{~nm}$; (b) $\mathrm{BHJ}$ active layer $=200 \mathrm{~nm}$; (c) BHJ active layer $=320 \mathrm{~nm}$. 
An AFM two-dimensional (2D) topography image of the $p$-DTS(FBTTh $)_{2}: \mathrm{PC}_{70} \mathrm{BM} \mathrm{BHJ}$ film (thickness $=320 \mathrm{~nm}$ ) is shown in Figure 5a. As reported, conjugated small molecules tend to aggregate strongly and form a crystalline structure $[1-4,8,20]$. Therefore, we assumed that the smaller domains in the device allow for a higher donor-acceptor interface area [1-4,8]. Finally, it has more efficient generations of charge carriers. From the literature, it has been suggested that below $15 \mathrm{~nm}$, morphology control of the high efficiency of the small molecular solar cell is guaranteed $[1-4,8]$. In Figure 5b, it confirms that avoiding solvent treatment is effectively working in the control of the BHJ domains within $3 \mathrm{~nm}$. Therefore, this would be strong and robust evidence of the morphology control of $\mathrm{BHJ}$ films without DIO solvent treatment.

a)

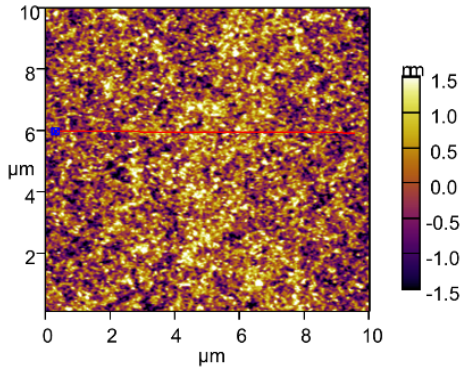

b)

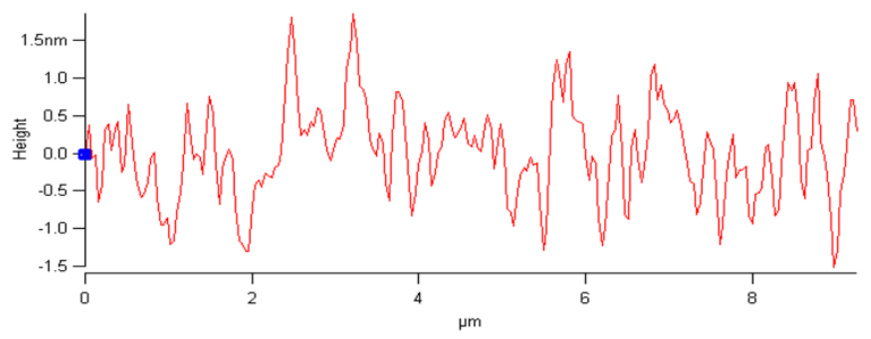

Figure 5. Measured atomic force microscopy (AFM) image of $\mathrm{BHJ}$ with a thickness of $320 \mathrm{~nm}$ : (a) top view of AFM; (b) measured cross-section of BHJ.

\section{Conclusions}

In conclusion, we studied the high performance of small-molecule organic solar cells without additive solvent treatment on the control of the photoactive layer in nano-morphology. Significantly, we have obtained small-molecule organic solar cells with a comparable PCE of $7.22 \%$ by eliminating the DIO additional solvent treatment. Also, GTMM analysis was accomplished to confirm the effect of the thickness variations of SM BHJ OSCs. Lastly, AFM measurement also confirms that smaller domains have achieved efficient charge generation. These results provide significant progress in showing that solution-processed small-molecule organic solar cells without solvent treatment can be an alternative method to having a high-PCE device with polymeric and/or small-molecule counterparts.

Author Contributions: I.K.K. and J.H.J. conceived and designed the experiments; I.K.K. performed the experiments; I.K.K. and J.H.J. analyzed the data; J.H.Y. contributed AFM analysis; I.K.K. wrote the paper.

Conflicts of Interest: The authors declare no conflict of interest.

\section{References}

1. Van der Poll, T.S.; Love, J.A.; Nguyen, T.Q.; Bazan, G.C. Non-Basic High-Performance Molecules for Solution-Processed Organic Solar Cells. Adv. Mater. 2012, 24, 3646-3649. [CrossRef] [PubMed]

2. Sun, Y.; Welch, G.C.; Leong, W.L.; Takacs, C.J.; Bazan, G.C.; Heeger, A.J. Solution-processed small-molecule solar cells with 6.7\% efficiency. Nat. Mater. 2012, 11, 44-48. [CrossRef] [PubMed]

3. Kyaw, A.K.K.; Wang, D.H.; Gupta, V.; Leong, W.L.; Ke, L.; Bazan, G.C.; Heeger, A.J. Intensity dependence of current-voltage characteristics and recombination in high-efficiency solution-processed small-molecule solar cells. ACS Nano 2013, 7, 4569-4577. [CrossRef] [PubMed]

4. Gupta, V.; Kyaw, A.K.K.; Wang, D.H.; Chand, S.; Bazan, G.C.; Heeger, A.J. Barium: An efficient cathode layer for bulk-heterojunction solar cells. Sci. Rep. 2013, 3. [CrossRef] [PubMed]

5. Zhang, Q.; Kan, B.; Liu, F.; Long, G.; Wan, X.; Chen, X.; Zuo, Y.; Ni, W.; Zhang, H.; Li, M. Small-molecule solar cells with efficiency over 9\%. Nat. Photon. 2015, 9, 35-41. [CrossRef]

6. Zhao, J.; Li, Y.; Yang, G.; Jiang, K.; Lin, H.; Ade, H.; Ma, W.; Yan, H. Efficient organic solar cells processed from hydrocarbon solvents. Nat. Energy 2016, 1. [CrossRef] 
7. Li, W.; Hendriks, K.H.; Roelofs, W.; Kim, Y.; Wienk, M.M.; Janssen, R.A. Efficient small bandgap polymer solar cells with high fill factors for $300 \mathrm{~nm}$ thick films. Adv. Mater. 2013, 25, 3182-3186. [CrossRef] [PubMed]

8. Kyaw, A.K.K.; Wang, D.H.; Gupta, V.; Zhang, J.; Chand, S.; Bazan, G.C.; Heeger, A.J. Efficient Solution-Processed Small-Molecule Solar Cells with Inverted Structure. Adv. Mater. 2013, 25, 2397-2402. [CrossRef] [PubMed]

9. Sharenko, A.; Proctor, C.M.; van der Poll, T.S.; Henson, Z.B.; Nguyen, T.Q.; Bazan, G.C. A High-Performing Solution-Processed Small Molecule: Perylene Diimide Bulk Heterojunction Solar Cell. Adv. Mater. 2013, 25, 4403-4406. [CrossRef] [PubMed]

10. Koster, L.; Smits, E.; Mihailetchi, V.; Blom, P. Device model for the operation of polymer/fullerene bulk heterojunction solar cells. Phys. Rev. B 2005, 72. [CrossRef]

11. Street, R.; Cowan, S.; Heeger, A. Experimental test for geminate recombination applied to organic solar cells. Phys. Rev. B 2010, 82. [CrossRef]

12. Cowan, S.R.; Street, R.; Cho, S.; Heeger, A. Transient photoconductivity in polymer bulk heterojunction solar cells: competition between sweep-out and recombination. Phys. Rev. B 2011, 83. [CrossRef]

13. Walker, B.; Kim, C.; Nguyen, T.Q. Small molecule solution-processed bulk heterojunction solar cells. Chem. Mater. 2010, 23, 470-482. [CrossRef]

14. Coffin, R.C.; Peet, J.; Rogers, J.; Bazan, G.C. Streamlined microwave-assisted preparation of narrow-bandgap conjugated polymers for high-performance bulk heterojunction solar cells. Nat. Chem. 2009, 1, 657-661. [CrossRef] [PubMed]

15. Tong, M.; Cho, S.; Rogers, J.T.; Schmidt, K.; Hsu, B.B.Y.; Moses, D.; Coffin, R.C.; Kramer, E.J.; Bazan, G.C.; Heeger, A.J. Higher molecular weight leads to improved photoresponsivity, charge transport and interfacial ordering in a narrow bandgap semiconducting polymer. Adv. Func. Mater. 2010, 20, 3959-3965. [CrossRef]

16. Ye, L.; Jing, Y.; Guo, X.; Sun, H.; Zhang, S.; Zhang, M.; Huo, L.; Hou, J. Remove the residual additives toward enhanced efficiency with higher reproducibility in polymer solar cells. J. Phys. Chem. C 2013, 117, 14920-14928. [CrossRef]

17. Burkhard, G.F.; Hoke, E.T.; McGehee, M.D. Accounting for interference, scattering, and electrode absorption to make accurate internal quantum efficiency measurements in organic and other thin solar cells. Adv. Mater. 2010, 22, 3293-3297. [CrossRef] [PubMed]

18. Zhao, X.; Li, Z.; Zhu, T.; Mi, B.; Gao, Z.; Huang, W. Structure optimization of organic planar heterojunction solar cells. J. Phys. D 2013, 46. [CrossRef]

19. Jo, J.H.; Chun, Y.-S.; Kim, I. Optical Modeling-Assisted Characterization of Polymer: Fullerene Photodiodes. IEEE Photonics J. 2014, 6, 1-7.

20. Liu, Y.; Zhao, J.; Li, Z.; Mu, C.; Ma, W.; Hu, H.; Jiang, K.; Lin, H.; Ade, H.; Yan, H. Aggregation and morphology control enables multiple cases of high-efficiency polymer solar cells. Nat. Commun. 2014, 5. [CrossRef] [PubMed]

(C) 2016 by the authors; licensee MDPI, Basel, Switzerland. This article is an open access article distributed under the terms and conditions of the Creative Commons Attribution (CC-BY) license (http://creativecommons.org/licenses/by/4.0/). 